\title{
Experimental mammalian Escherichia coli K1 meningitis
}

\author{
${ }^{1}$ Qasim N. O. Thewaini , ${ }^{2}$ Sura I. A. Jabuk \\ ${ }^{3}$ Dallal M. M. Ishwalyia \\ University of Babylon, College of Science, Department of Biology Hilla, Iraq. ${ }^{1,2,3}$
}

\begin{abstract}
Escherichia coli (E. coli) is the most common gram-negative organism causing meningitis during the neonatal period. Neonatal meningitis due to E coli $K 1$ is a serious illness with unchanged morbidity and mortality rates for the last few decades. The mechanism involved in the pathogenesis of E. coli meningitis remains unclear. Experimental studies with animal models have given new insights into its pathophysiology during the acute phase of the disease . E. coli strain originally isolated from the Cerebrospinal fluid of a child with 20 days old was complaining acute meningitis. In the present work, we describe in detail a simple, reproducible and efficient method to induce E.coli meningitis in mice by using the three route (intrapretonium, intravenous, oral) of infection. E.coli were recovered of same characters of the original isolate used for preparing the infective dose. The histopathological changes found in the experimentally infected mice we can conclude induce meningeal thickening, neutrophiles infiltration, hemorrhages and leukocyte infiltration in brain.
\end{abstract}

Key word: bacterial Meningitis, Cerebrospinal fluid, Escherichia coli kl, histopathology

\section{Introduction}

Bacterial meningitis is recognized as one of the leading causes of infection-related death, and this disease still continues to be a significant health concern (1). Bacterial meningitis is a fatal and serious infection of the central nervous system (CNS) (2).The underlying pathophysiological mechanisms implicated in the development of meningitis are quite complex and remain poorly understood . Bacterial meningitis is associated with high mortality and morbidity, even when treated with antibiotics(3).

The mortality occurs in $25 \%$ to $35 \%$ of all patients, and long-term neurological and neuropsychological sequelae are reported to affect up to $50 \%$ of survivors(4). These complications include intracranial hypertension caused by brain edema or hydrocephalus, arterial and venous cerebrovascular alterations (cerebral ischemia, venous thrombosis), intracranial hemorrhage, mental retardation, focal neurological deficits, hearing impairment, and systemic spread of bacteria leading to septic shock and multiorgan failure (5).

Escherichia coli K1 is the most common cause of meningitis in premature infants $(46 \%)$, whereas it is the second most common agent in full term neonates (15\%) (6). Mortality rates of 5\% are recorded in children in the developed world, but these rise to $30 \%$ in developing countries (7). E.coli K1 causes meningitis in neonates, which remains a significant problem for the last few decades with case fatality rates ranging from 5 to $40 \%$ of infected neonates (8). Despite treatment with advanced antibiotics, up to $30 \%$ of survivors exhibit neurological sequelae such as hearing impairment, mental retardation, and hydrocephalus. Furthermore, due to the emergence of antibiotic resistant strains, mortality rates may significantly increase in future(9).

The crossing of the mucosal epithelium and the invasion of small sub epithelial blood vessels by E. coli K1 represent critical early steps in the pathogenesis of meningitis. During initial colonization, E.coli K1 encounters several host defense mechanisms such as complement, neutrophils, and $M \varnothing$ on its path to the bloodbrain barrier (BBB). However, very little is known about the mechanisms by which E. coli K1 finds a niche to avoid these host defenses (10).

The emergence of multi drug resistant E. coli $\mathrm{K} 1$ has further increased the incidence of these infections. (11). Numerous mediators have been implicated in the complex pathophysiologic processes of E. coli K1 meningitis such as inflammatory cytokines, arachidonic acid metabolites, platelet-activating factor, and nitric oxide (NO) (7).

A recent surge in antibiotic resistant strains of E. coli K1 may significantly increase the mortality and morbidity rates. In addition, the prognosis of meningitis is difficult until the bacteria reach the cerebrospinal fluid (CSF), by which time greater amounts of proinflammatory cytokines are circulating in the blood and the progression of brain damage has begun (12). In the present work a report on case of E.coli K1 meningitis in newborn infant and experimental pathogenecity in mouse model were made. 
1-Patient:

\section{Materials \& Methods}

The E. coli strain originally isolated from the CSF of a child with 20 days old was complaining acute meningitis with subtle signs such as fever, lethargy, vomiting and altered mental status ranging from sleepiness to coma (13). One tube of CSF was collected for culture , Bacteria were grown overnight on blood agar plates, harvested in $0.9 \%$ saline and stored at $-80^{\circ} \mathrm{C}$. Frozen aliquots were used for the experiments and diluted with saline to the required bacterial concentration (14).

\section{2-Clinical bacteriology:}

Each specimen was immediately inoculated on blood agar, nutrients agar, MacConkey's agar . All plates were incubated aerobically at $37^{\circ} \mathrm{C}$ for $24-48$ hours. Gram stain of smears of each specimen were done after incubation on plates. Morphologies of these isolates were studied (15). Identification of bacterial isolates was confirmed by using Api 20 E test system (Biomerieux-France) and serological by specific antisera.

\section{3-Bacterial inoculum preparation}

Bacterial inoculum was prepared from a pure culture according to E.coli was grown in nutrient agar at $37 \mathrm{C}^{\circ}$ for 24 hours under aerobic condition. By using phosphate buffer saline prepare bacterial suspension was adjusted with Macfarland tube No. 5 to a concentration of approximately $1 * 10^{5} \mathrm{CFU} / \mathrm{ml}(14)$.

\section{4-Experimental E.coli infection of mouse}

Twelve BALB/c mice were 7-8 weeks old, when challenged. Body weight was 25-30 g. They were obtained from animal house, College of science, Babylon University. The mice were housed in an air conditioned room with 12 hour light, 12 hour dark cycle. They were fed a commercial rodent diet with free access to drinking water. Twelve mouse were divided into three groups.

First group : consisted of three mice were each inoculated orally with $0.5 \mathrm{ml}$ of $10^{5}$, CFU of bacteria suspension . Control mice received $0.5 \mathrm{ml}$ of phosphate buffer saline through the same route.

Second group: consisted of three mice were each injection peritoneum with $0.5 \mathrm{ml}$ of $10^{5} \mathrm{CFU}$ of bacteria suspension. Control mice received $0.5 \mathrm{ml}$ of phosphate buffer saline through the same route.

Third group: consisted of three mice were each injection vein with $0.5 \mathrm{ml}$ of $10^{5}$, CFU of bacteria suspension . Control mice received $0.5 \mathrm{ml}$ of phosphate buffer saline through the same route $(16,17,14)$.

\section{5-bacterial reisolation:}

swab samples obtained aseptically from the brain . These biopsy samples were homogenized by using a sterile lancets and needles. These homogenized tissues were plated onto the E.coli selective medium, and incubated at $37 \mathrm{C}^{\circ}$ for 24 under aerobic condition. Growing bacteria were identified by Gram staining, morphology and other biochemical tests (16).

\section{6-Tissue preparation}

Histological section preparation of infected animals was achieved according to (18) method which includes Fixation, Dehydration, Clearing, Impregnation, Embedding and blocking, Section cutting and Staining.

\section{1-Bacteriology:}

\section{Result}

Colony morphology: small 2-3 mm diameter, circular in shape, regular margin, flat, smooth, lactose fermenting on MacConkey's agar, Green metallic sheen on Eosin methylin blue.

Gram staining: Gram-negative rods uniformly stained with no particular arrangement . motile bacteria in hanging drop preparation.

Biochemical reactions: Oxidase negative, catalase positive, glucose fermentation, and gas production, reduces nitrates to nitrites, indole positive, methyl red positive, Voges-Proskauer negative, citrate not utilized, lactose fermenter, triple sugar iron agar showed slant yellow with gas production, lysine decarboxylase test positive. serological tests :The result shows the isolated E.coli belong to the serotype (O18: K1: H7).

\section{2- pathogenicity:}

Mouse meninges model was made . it was susceptible to E.coli k1by this model causes acute and subacute meningitis through three routes (oral, peritoneum, vein) with in 14 days post injection table -1-. 
Table -1- clinical features of experimentally infected mouse

\begin{tabular}{|c|c|}
\hline Days post IV, IP, Orally & Manifestation \\
\hline 1-Gross & Fever \\
\hline 3 & Fever, neurogical signs \\
\hline 5 & Subtle signs, neck \&legs were flexed \\
\hline 7 & Altered mental status\& neurogical signs \\
\hline 14 & Visceral organ, meningeal thinking with brain congestion \\
\hline 2- postmortem
\end{tabular}

At the 5,10 and14 post infection the CSF culture were positive to E.coli as pure scanty to moderate growth. On autopsy anther days 5,10,14 post infection and positive to E.coli (table 2).

Table -2-The reisolation \& growth of E.coli k1pathogens isolated from CSF

\section{N.G: No growth}

\begin{tabular}{|c|c|c|c|}
\hline \multirow{2}{*}{ Route of injection } & \multicolumn{3}{|c|}{ Growth characteristic /days } \\
\cline { 2 - 4 } & $\mathbf{5}$ & $\mathbf{1 0}$ & $\mathbf{1 5}$ \\
\hline Oral & N.G & N.G & Scanty \\
\hline Vein & Scanty & Moderate & Moderate \\
\hline Peritoneum & N.G & Scanty & Moderate \\
\hline Control & N.G & N.G & N.G \\
\hline
\end{tabular}

\section{3- Histophathology :}

Tissue from E.coli K1 infected mice after 15 day post infection were prepared, stained, mounted and examined as following:

1- peritoneum route:
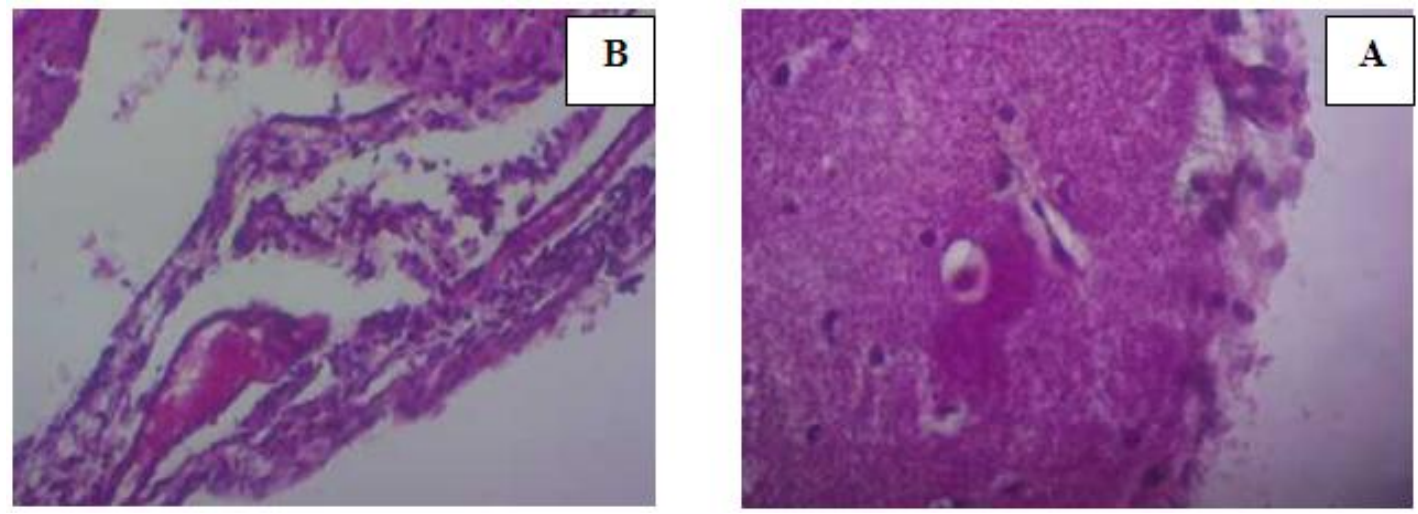

Figure-1-Cross section in brain of mice injection in peritoneum with E.coli showed (A):Meningeal thickening and neutrophil infiltration . (B) sub-arachnoid meningeal inflammation stained with hematoxylin and eosin (H\&E), Magnification power 40

2- intravenous route:
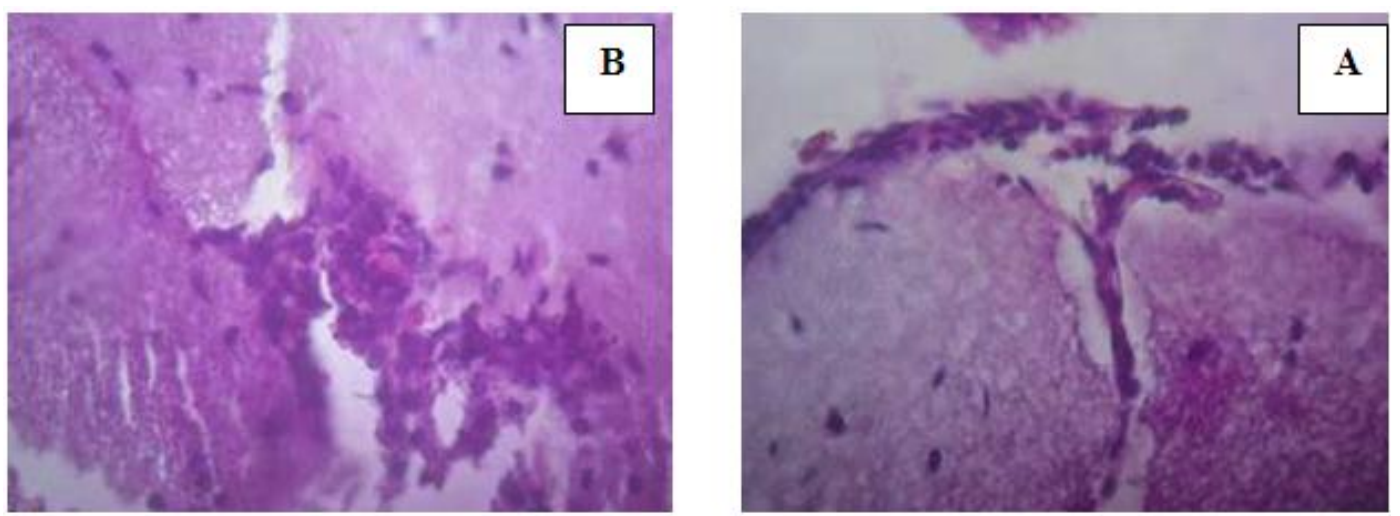

Figure -2-Cross section in brain of mice intravenous injection with E.coli showed (A) Meningeal thickening and neutrophil infiltration $(B)$ hemorrhages and leukocyte infiltration stained with hematoxylin and eosin (H\&E) Magnification power $400 \mathrm{X}$. 


\section{3- Oral route:}
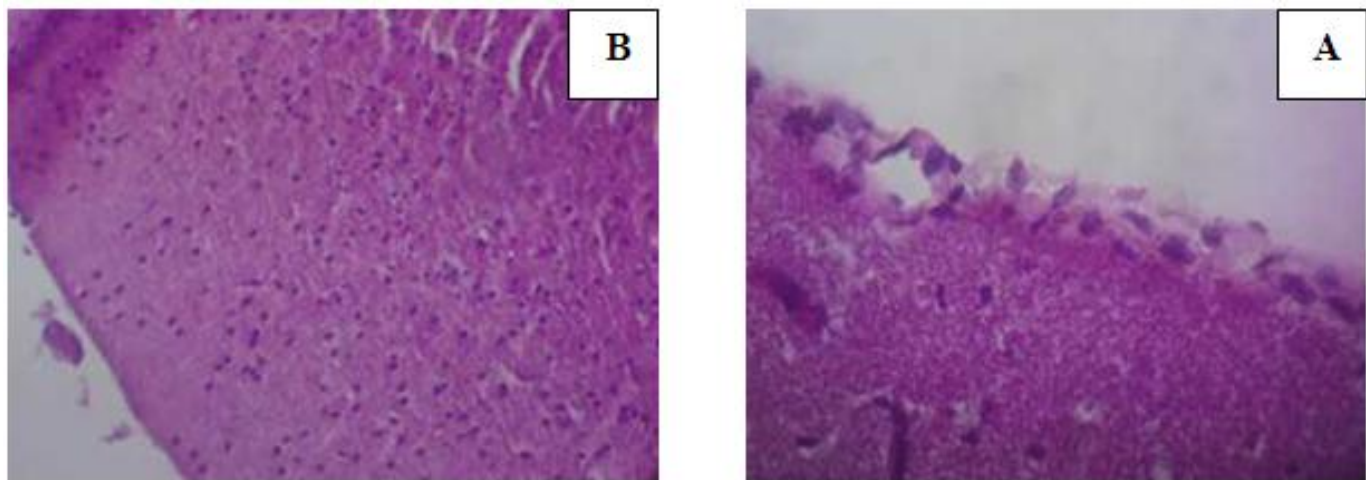

Figure -3 -(A) Cross section in brain of mice oral injection with E.coli showed Meningeal thickening and neutrophil infiltration (B) Cross section in brain of mice injection with phosphate buffer saline (control) stained with hematoxylin and eosin $(\mathrm{H} \& \mathrm{E})$ Magnification power $400 \mathrm{X}$.

\section{Discussion}

The nature of the infection and the characteristic of the pure isolate are consistent with E.coli k1 (6). Acute bacterial meningitis is most often caused by E.coli \& Streptococcus pneumoniae in neonates (19).

E.coli were recovered of same characters of the original isolate used for preparing the infective dose . At the day 10\& 14 post infection the CSF were positive for E.coli as pure scanty to moderate growth . Similar findings were reported by(16).

On autopsy at the day 14 post intrapretoneal, oral \& vein inoculation in mice induce meningeal thickening, neutrophiles infiltration \& vascular congestion in brain. These pathological aspects in mouse model are similar to those observed in Ecoli k1 infected human and another animals models $(20,21)$

According to those bacteriological revolution and histopathological changes found in the inflamed meninges of experimentally infected mice we can conclude this changes closely resemble those found in E.coli k1 infected human meningitis. Therefore the mice may represent useful model for understanding the pathogenesis of E.coli related acute human meningitis. Also this work give approve for intravenenous, intrapretoneal and oral routes of infection in mice.

\section{References}

[1]. Nathan, B. R. \& Scheld, W. M. (2000) New advances in the pathogenesis and pathophysiology of bacterial meningitis. Curr. Infect. Dis. Rep. 2: 332-336.

[2]. Somand, D.\& Meurer, W.(2009). Central nervous system infections. Emerg. Med. Clin. North Am. 27:89-100.

[3]. Sinner, S.W.\& Tunkel, A.R.;(2004) Antimicrobial agents in the treatment of bacterial meningitis. Infect. Dis. Clin. North Am., 18:581-602.

[4]. Tebruegge, M.\& Curtis, N.(2008). Epidemiology, etiology, pathogenesis, and diagnosis of recurrent bacterial meningitis. Clin Microbiol. Rev.

[5]. Scheld, W.M.; Koedel, U.; Nathan, B.\& Pfister, H.W.(2002). Pathophysiology of bacterial meningitis: mechanism(s) of neuronal injury. J. Infect. Dis. 186: 225-233.

[6]. Bonacorsi, S.\& Bingen, E. (2005). Molecular epidemiology of E. coli causing neonatal meningitis. Int. J. Med. Microbiol. 295:373381

[7]. Houdouin, V.; Bonacorsi, S.; Bidet, P.; Blanco, J.; De La Rocque, F.; Cohen,R.; Aujard, Y.\& Bingen, E.(2008). Association between mortality of E.coli meningitis in young infants and non-virulent clonal groups of strains. Clin. Microbiol. Infect. 14:685690.

[8]. Stoll, B.J.; Hansen, N.; Fanaroff, A.A.; Wright, L.L.\& Carlo, W.A. (2002). Changes in pathogens causing early-onset sepsis in very-low-birth-weight infants. N. Engl. J. Med. 347: 240-247.

[9]. Prasadarao, N.V.; Blom ,A.M.; Villoutreix, B.O.\& Linsangan, L.C. (2002) A novel serum resistance of E. coli K1. J .Immunol. 169: 6352-6360.

[10]. Wooster, D.G.; Maruvada, R.; Blom ,A.M\& Prasadarao, N.V. (2006). Logarithmic phase E.coli K1 efficiently avoids serum killing by promoting C4bpmediated C3b and C4b degradation. Immun. 117: 482-493.

[11]. Bizzarro, M.J.; Dembry, L.M.; Baltimore ,R.S.\& Gallagher, P.G.(2008). Changing patterns in neonatal E. coli sepsis and ampicillin resistance in the era of intrapartum antibiotic prophylaxis. Pediatrics .121:689-696.

[12]. Dubois, D.; Prasadarao, N.V. ; Mittal, R.; Bret, L.; Roujou-Gris, M. \& Bonne, R. (2009). The emergence of CTX-M-producing E.coli K1 changes the paradigm of virulence and antibiotic multi-resistance. Emerg. Infect. Dis. 15:1988-1990.

[13]. Kumar, D.; Amit, K.S.; Mohammad, R. A. and Yogesh, C.(2014). Antimicrobial Susceptibility Profile of Extended Spectrum $\beta$ Lactamase (ESBL) Producing E. coli from Various Clinical Samples. Infec.Dis.: Res.and Trea. $7: 1-8$.

[14]. Ribes , S. ; Tanja, M.; Martina, O.; Sandra, R.; Hana, J.; Uwe-Karsten, H.; Stefan, N. and Roland, N.(2014). Intraperitoneal prophylaxis with $\mathrm{CpG}$ oligodeoxynucleotides protects neutropenic mice against intracerebral E.coli K1 infection Journal of Neuroinflammation . 11(14)1-11.

[15]. Assegid, M.; Johannes, G.; Gottfried, U.; Christophine, N.; Kennedy, K.; Lazarus, I.; Francis, K.; Christopher, N.; David, M.; Mohan, P. J.and Evans, S. (2013). Antimicrobial sensitivity patterns of cerebrospinal fluid (CSF) isolates in Namibia: implications for empirical antibiotic treatment of meningitis J. of Pharma.Polic.and Prac. 6(4):1-10. 
[16]. Kelly, A.; Tivendale, C. M. ; Logue, S.; Kariyawasam, D.; Jordan, A. ; Hussein, G.; Li, Y.W. and Lisa, K. N. (2010). AvianPathogenic E. coli Strains Are Similar to Neonatal Meningitis E. coli Strains and Are Able To Cause Meningitis in the Rat Model of Human Disease. Ame. Soc. for Microbiol.78(8) 3412-3419.

[17]. Val, T.; Hill, S.M.; Townsend, R. S.; Arias, J . M.; Jenabi, I.G. ; Hiroyuki S. and Julie, L. (2004). Dependent E.coli K1 Interactions with Professional Phagocytes Are Important for Early Systemic Dissemination of Infection in the Neonatal Rat. Amer. Soc.for Microbiol. 72(1):478-488.

[18]. Mohan, H. (2007). Pathology Practical Book. $2^{\text {second }}$ ed. Medical publisher(P) LTD, New Delhi .p: 1-15

[19]. Denis, G.; Oliver, S.; Martin, G. T. \& Stephen L. L. (2007) An infant mouse model of brain damage in pneumococcal meningitis. Acta Neuropathol 114:609-617.

[20]. Ke Zhang, W. ; Qiang, L. ; Wen-Gang, F.; Li, Z.; De-Shu, S. and Yu-Hua, C. (2009). Tentative identification of glycerol dehydrogenase as E. coli K1 virulence factor cglD and its involvement in the pathogenesis of experimental neonatal meningitis Med. Microbiol. Immunol. 198:195-204.

[21]. Mittal, I. G .;Kerstin, A. ; G. and Nemani, V. P.(2010). Inhibition of Inducible Nitric Oxide Controls Pathogen Load and Brain Damage by Enhancing Phagocytosis of E. coli K1 in Neonatal Meningitis. The Ame. J. of Patho., 176( 3 ): $1292-1305$. 